\title{
The Health and Social Care Act 2012: what will it mean for mental health services in England?
}

\author{
Frank Holloway ${ }^{1}$
}

The Psychiatrist (2012), 36, 401-403, doi: 10.1192/pb.bp.112.040378

${ }^{1}$ South London and Maudsley NHS Foundation Trust, London, UK Correspondence to Frank Holloway (f.holloway1@gmail.com)

First received 8 Jun 2012, accepted 12 Jul 2012

\begin{abstract}
Summary The Health and Social Care Act 2012 brings in profound changes to the organisation of healthcare in England. These changes are briefly described and their implications for mental health services are explored. They occur as the National Health Service (NHS) and social care are experiencing significant financial cuts, the payment by results regime is being introduced for mental health and the NHS is pursuing the personalisation agenda. Psychiatrists have an opportunity to influence the commissioning of mental health services if they understand the organisational changes and work within the new commissioning structures.
\end{abstract}

Declaration of interest F.H. is a member of the NHS Consultants' Association.
All healthcare professionals working in England should be aware of the controversy surrounding the latest Health and Social Care Bill, which became an Act on 27 March 2012 after a very protracted passage through Parliament. Perhaps too late in the day to have significant political effect, a raft of professional organisations including the British Medical Association, the Royal College of General Practitioners and the Royal College of Psychiatrists eventually came out against the Bill. The Act has, however, been much amended in its passage through Parliament, perhaps for the better. ${ }^{1}$

The Health and Social Care Act 2012 sets out profound changes to the structure of the National Health Service (NHS) in England, although not in the three other devolved administrations in the UK. It is very long (457 pp.), much of it amending previous Acts, and is extremely complex. Chris Ham, Chief Executive of the King's Fund, in an editorial in the British Medical Journal, likened summarising the Act to 'paraphrasing War and Peace on Twitter.'. Further layers of complexity are added by the evolving implementation of the Act through Parliamentary Regulations and decisions by the Department of Health and the NHS Commissioning Board. Familiar acronyms such as PCT ('primary care trust') and SHA ('strategic health authority') will be replaced by a blizzard of new ones.

\section{New systems for healthcare management and commissioning}

The headline changes relate to the management and commissioning of healthcare. The previous structure, which had the Department of Health setting policy and budgets, strategic health authorities responsible for an overview of performance within large geographical areas and primary care trusts engaged in local commissioning, is swept away. The Department of Health will still exist but the centre of gravity will move to the NHS Commissioning
Board, which was already in place in shadow form before the Act was passed. The Board, which includes key players from the former Department of Health structures, will oversee the work of a proposed 212 clinical commissioning groups (CCGs). It will have four regions and, it has recently been announced, 27 'local area teams' (LATs) - closely reflecting the 28 strategic health authorities in place between 2002 and 2006. A smaller number of LATs will have a role in commissioning specialised services on behalf of a grouping of LATs - this is relevant to mental health services because of responsibilities the NHS Commissioning Board will have in commissioning highly specialised mental health services and secure services. Some commentators have noted that these massive organisational changes have resulted in a management configuration for the NHS rather similar to previous structures (with a couple of added layers) in a classic case of 'Plus ça change (plus c'est la même chose)'.

Clinical commissioning groups will be responsible for commissioning primary and secondary care and during 2012-2013 have to go through an elaborate authorisation process, which includes the requirement to set out in the application their commissioning arrangements for 'people who need support with mental health'. ${ }^{3}$ The population of each CCG will range from 90000 to $900000,{ }^{4}$ with a mean population of just under 250000 . Commissioning is seen as a complex process, involving planning services (based on assessment of needs), contracting with healthcare providers and monitoring their performance against agreed service specifications. $^{5}$ The plan is that commissioning support services (CSSs), initially based on former PCT clusters, will help CCGs (which will have very limited infrastructure) and the NHS Commissioning Board in undertaking their 'transactional' (e.g. contracting) and 'transformational' (e.g. service improvement and redesign) functions. In parallel with the accreditation of CCGs there is a process of accrediting CSSs, which are initially to be hosted by the 
NHS Commissioning Board. In the longer term, commissioning support 'will operate within a competitive and market environment ${ }^{5}$ (p. 10) and will be sourced from a range of providers as well as, for larger CCGs, in-house resources. The NHS Commissioning Board states that 'niche commissioning support offers' may develop 'providing specialist subject matter expertise for particular services or functions, for example in the areas of mental health, continuing care and safeguarding or health economics and specialist procurement advice $^{5}$ (p. 11).

\section{The primacy of choice agenda}

At the heart of the government's thinking on reform of the NHS is a belief in the importance of choice and competition between providers. ${ }^{2}$ In itself this should bring few concerns to the mental health sector, which is already highly diversified. The existing regulator of NHS foundation trusts, Monitor, will become an economic regulator for providers of NHS-funded care. Monitor is tasked with preventing anticompetitive behaviour in the provision of healthcare services, licensing providers (along with the Care Quality Commission) and managing provider failure, ${ }^{2}$ while at the same time 'enabling health care services provided for the purposes of the NHS to be provided in an integrated way' (Health and Social Care Act Section 62.4). Quite what this duty will mean in practice is unclear. Another major role for Monitor will be, along with the NHS Commissioning Board, to set the national tariff. Mental health services are to come within the payment by results framework, ${ }^{6}$ although a recent review of the readiness of providers to implement the regime identified serious operational challenges $^{7}$ (to say nothing of the intellectual difficulties surrounding mental health payment by results, which are formidable ${ }^{8}$ ).

\section{Changes in the secondary care sector, education and training}

There are to be many other changes to the health and social care landscape. Within the NHS, secondary care providers are expected to become foundation trusts by $2014 .^{9}$ It is probable that those that cannot achieve this on their own will be absorbed into existing foundation trusts or newly created entities in a process that will undoubtedly preoccupy senior management at a time of enormous challenge for the NHS as a whole. Public health becomes a local authority responsibility, with a requirement that has historical resonance to appoint a Director of Public Health. Public Health England, a special health authority accountable to the Secretary of State, will oversee the public health system. Local authorities are also to set up 'health and well-being boards' with a remit to understand local needs and priorities and encourage commissioners to 'work in a more joined up way'. The National Institute for Health and Clinical Excellence (NICE), which already provides guidance to commissioners, ${ }^{10}$ retains its acronym but becomes the National Institute for Health and Care Excellence, taking on the role for social care currently provided by the Social Care Institute for Excellence. There will also be profound changes to healthcare education and training, with the work of Postgraduate Deaneries being absorbed by local education and training boards, working to Health Education England, yet another new special health authority. The Care Quality Commission will lose its role in assessing NHS commissioners but will host Healthwatch England, intended to be a national focus for the views of patients about their care that works with local Healthwatch organisations. In response to a 'listening exercise' that took place before the Act was passed, there will also be 'clinical senates', perhaps 15 across England. These have an unclear constitution, role and function but are expected to have some influence on the plans of the NHS Commissioning Board and CCGs.

\section{Transformations in mental health services}

What will these changes mean for mental health services? We are in an era of uncertainty as the previous structures, whether they worked well or badly, are being dismantled. The uncertainty is compounded by the concurrent implementation of payment by results in mental health and the personalisation agenda. ${ }^{11}$ Hitherto good joint working relationships between local authorities and health services appear to be unravelling, which is particularly problematic for mental health services. Previous relationships developed by providers with primary care trusts and strategic health authorities will be replaced with a complex network of relationships with CCGs, CSSs, LATs and ultimately the NHS Commissioning Board. Influencing the commissioning process will be crucial.

Commissioners (the CCGs and NHS Commissioning Board, whose specialist commissioning role will be devolved to the LATs) will have a very difficult role in a time of diminishing real resources for health and social care. They will have access to comment and advice from many statutory bodies including NICE, Healthwatch, health and well-being boards, Public Health England, CCSs, Care Quality Commission and the clinical senates. However, none of these bodies have any track record in the provision of high-quality advice in relation to the organisation of mental healthcare (advocates of NICE and Care Quality Commission might disagree with this statement). Commissioners will need to be alert to the possibility of 'gaming' across funding streams, a problem encountered in other mental health payment by results systems: ${ }^{8}$ it is all too predictable that yet more patients will be pushed down forensic care pathways from which return to mainstream care will be difficult. The management of 'high-cost, low-volume' cases is particularly problematical for commissioners and psychiatry throws up a lot of these; many of these patients end up being treated out of area.

The Royal College of Psychiatrists has been proactive in producing material to help commissioners, most effectively through partnerships with other bodies. Important products of this work include In Sight and in Mind: A Toolkit to Reduce the Use of Out of Area Mental Health Services ${ }^{12}$ and a series of papers that are being produced by the Joint Commissioning Panel for Mental Health, which is hosted by the College (published work to date is available at www.jcpmh.info). 
Psychiatrists working in England will need to become familiar with the new health and social care landscape and to work with a new set of commissioners. At a higher level it will be important that commissioners (at the level of the CCG, the LAT and NHS Commissioning Board) have access to authoritative, clinically informed advice about the very complex tasks they are undertaking. Policy makers and practitioners working in other jurisdictions will learn from the journey that mental healthcare in England is undertaking.

\section{About the author}

Dr Frank Holloway, Emeritus Consultant Psychiatrist, South London and Maudsley NHS Foundation Trust, London, UK.

\section{References}

1 Bailey S. The Health Bill passes. Royal College of Psychiatrists, 2012 (http://www.rcpsych.ac.uk/members/thepresidentsblog/ thehealthbillpasses.aspx).

2 Ham C. What will the Health and Social Care Bill mean for the NHS in England? BMJ 2012; 344: e2159.

3 NHS Commissioning Board. Clinical Commissioning Group Authorisation: Draft Guide for Applicants. NHS Commissioning Board, 2012.
4 NHS Commissioning Board. Clinical commissioning groups: proposed configurations agreed. NHS Commissioning Board, 2012 (http:// www.commissioningboard. nhs.uk/2012/05/31/ccg-configs-agreed/).

5 NHS Commissioning Board. Developing Commissioning Support. Towards Service Excellence. NHS Commissioning Board, 2012.

6 Department of Health Payment by Results Team. Mental Health Clustering Booklet (V2.03) (2012/13) Gateway Reference 17250. Department of Health, 2012.

7 NHS Confederation. Mental Health Payment by Results Readiness Review. NHS Confederation, 2011 (http://www.nhsconfed.org/Publications/ Documents/PbR_241111.pdf).

8 Mason A, Goddard M, Myers L, Verzulli R. Navigating uncharted waters? How international experience can inform the funding of mental health care in England. J Ment Health 2011; 20: 234-48.

9 BMA Parliamentary Unit. What We Know So Far .. . Health and Social Care Act 2012 at a Glance. BMA, 2012.

10 National Institute for Health and Clinical Excellence. Service for the Treatment and Management of Schizophrenia in Adults. Commissioning Guide. NICE, 2009 (http://www.nice.org.uk/media/243/B9/ AdultSchizophreniaCommissioningGuide.pdf).

11 Cameron A. Getting it Together for Mental Health Care: Payment by Results, Personalisation and Whole System Working. National Development Team for Inclusion, 2012 (http://www.ndti.org.uk/ uploads/files/Pbr_and_pers_Final_v2.pdf).

12 Ryan T, Davies G, Bennett A, Meier R, Killaspy H. In Sight and In Mind: A Toolkit to Reduce the Use of Out of Area Mental Health Services. National Mental Health Development Unit, 2011 (http://www.rcpsych.ac.uk/pdf/ insightandinmind.pdf). 